\title{
Lipophilic Extracts from Banana Fruit Residues: A Source of Valuable Phytosterols
}

\author{
Lúcia Oliveira, ${ }^{*}{ }^{\dagger}, *$ Carmen S. R. Freire, ${ }^{\dagger}$ Armando J. D. Silvestre, ${ }^{\dagger}$ And \\ NEREIDA CORDEIRO
}

CICECO and Department of Chemistry, University of Aveiro, 3810-193 Aveiro, and CEM and Department of Chemistry, University of Madeira, 9000-390 Funchal, Portugal

\begin{abstract}
The chemical composition of the lipophilic extracts of unripe pulp and peel of banana fruit 'Dwarf Cavendish' was studied by gas chromatography-mass spectrometry. Fatty acids, sterols, and steryl esters are the major families of lipophilic components present in banana tissues, followed by diacylglycerols, steryl glucosides, long chain fatty alcohols, and aromatic compounds. Fatty acids are more abundant in the banana pulp (29-90\% of the total amount of lipophilic extract), with linoleic, linolenic, and oleic acids as the major compounds of this family. In banana peel, sterols represent about $49-71 \%$ of the lipophilic extract with two triterpenic ketones (31-norcyclolaudenone and cycloeucalenone) as the major components. The detection of high amounts of steryl esters $(469-24405 \mathrm{mg} / \mathrm{kg})$ and diacylglycerols $(119-878 \mathrm{mg} / \mathrm{kg})$, mainly present in the banana peel extract, explains the increase in the abundance of fatty acids and sterols after alkaline hydrolysis. Several steryl glucosides were also found in significative amounts $(273-888 \mathrm{mg} / \mathrm{kg})$, particularly in banana pulp $(888 \mathrm{mg} / \mathrm{kg}$ ). The high content of sterols (and their derivatives) in the 'Dwarf Cavendish' fruit can open new strategies for the valorization of the banana residues as a potential source of highvalue phytochemicals with nutraceutical and functional food additive applications.
\end{abstract}

KEYWORDS: Musa acuminata Colla; 'Dwarf Cavendish'; banana pulp; banana peel; fatty acids; sterols; diacylglycerols; steryl glucosides; steryl esters

\section{INTRODUCTION}

Banana plants are cultivated in more than 100 countries throughout the tropical and subtropical regions, occupying around 10 million hectares, with an annual fruit production of approximately 88 million metric tons (1). Bananas are the fourth most important food crop in developing countries, after rice, wheat, and maize, with nearly $90 \%$ of the crops being grown for small-scale consumption and local trade (2). Despite the fact that bananas are the world's most traded fruit, international exports involve almost exclusively the 'Cavendish' variety, which, however, accounts for only around 13\% of global banana production. The remaining $87 \%$ involves a wide range of varieties, adapted to specific environmental conditions and selected for local trade (2).

In Madeira Island (Portugal), banana plantations contribute significantly to the regional economy. Among the cultivated species, 'Dwarf Cavendish' (Musa acuminata Colla var. cavendish) is nowadays the most important species in terms of occupied area and productivity, comprising ca. $60 \%$ of the total local banana production. After the harvesting of the single bunch of bananas, a

* To whom correspondence should be addressed. Tel: +351 234 370 711. Fax: +351234 3700 84. E-mail: 1.oliveira@ua.pt.

${ }^{\dagger}$ University of Aveiro.

${ }^{\ddagger}$ University of Madeira. great amount of agricultural residues are produced. Together with the banana plant residues (pseudostem, foliage, and rachis) that are usually left in the soil plantation, significant amounts of unripe banana residues are produced during their selection process. After the arrival of unripe banana bunches at central collection stations, bananas too small for shipping are removed, along with those that have damaged or spoiled areas that could cause microbial contamination of the bunch. Rejected bananas are normally improperly disposed, as the common practice of handling waste bananas is to dispose of them as garbage.

Banana production residues are nowadays used only to a limited extent to produce low-value products such as flours, dried pulps, and jams in animal feed, or they are eventually composted $(3,4)$. Other attempts to drain these defective fruits and give added value to them involve their processing for the production of ethanol $(5,6)$ and methane $(7)$ and as adsorbents for water purification (8). Therefore, the development of new applications for these agricultural residues could be an interesting income for banana producers and for regional economies.

As part of a project aiming to find new applications for the residues produced after banana fruits harvesting, we have been studying the chemical composition of the plant tissues from different morphological regions of 'Dwarf Cavendish', harvested on Madeira Island $(9-13)$. These studies have shown some interesting features, particularly in the composition of fatty acids, 
sterols, and steryl glucosides $(9,10)$. Because some of these compounds and, particularly, sterols and steryl glucosides, present interesting benefits to human health (14), banana plants have been shown to be a potential source of valuable phytochemicals $(9,10)$.

Despite the fact that several studies dealing with lipids, namely, the sterols composition of banana pulp and peel of other Musa species, have been already published (15-25), the lipophilic extractives from banana pulp and peel of 'Dwarf Cavendish' have not yet been studied. Following these studies and considering the scarcity of information about the composition of 'Dwarf Cavendish' banana fruits, in the present study, the lipophilic fraction of banana 'Dwarf Cavendish' fruit residues (unriped pulp and peel) was analyzed by gas chromatography-mass spectrometry (GC-MS). The results obtained show that among the lipophilic extractives, these byproduct fractions can be considered an important source of phytosterols, namely, of free sterols, steryl esters, and steryl glucosides, which can be bioactive components for nutraceutical and functional food applications.

\section{MATERIALS AND METHODS}

Chemicals. Potassium hydroxide (puriss, p.a., $\geq 86 \%$ ), hydrochloric acid (puriss, p.a., fuming, $\geq 37 \%$ ), methanol (puriss, p.a., absolute, $\geq 99.8 \%$ ), and icosan-1-ol (98\% purity) were purchased from Fluka Chemie (Madrid, Spain). Dichloromethane (99\% purity), pyridine (99\% purity), bis(trimethylsilyl)trifluoroacetamide (99\% purity) and trimethylchlorosilane (99\% purity), stigmasterol (95\% purity), palmitic acid (99\% purity), and tetracosane (99\% purity) were supplied by Sigma Chemicals Co. (Madrid, Spain).

Samples Preparation. Unripe and defective banana fruits $(5 \mathrm{~kg})$, from banana plant 'Dwarf Cavendish', were randomly selected from a banana processing cooperative in Funchal (Madeira Island). Peels and pulps were handily separated, frozen with liquid nitrogen, and lyophilized immediately after sampling. The samples were milled and stored in an exsicator until analysis $\left(25^{\circ} \mathrm{C}, 55 \%\right.$ relative humidity). The moisture content of the samples was calculated on the basis of weight loss after the sample had been heated in an oven at $105{ }^{\circ} \mathrm{C}$.

Extraction. Three aliquots $(20 \mathrm{~g})$ of the powdered samples was Soxhlet extracted with dichloromethane $(200 \mathrm{~mL})$ for $6 \mathrm{~h}$. The solvent was evaporated to dryness, and the extracts were weighed. The results were expressed in percent of dry material.

Alkaline Hydrolysis. About $20 \mathrm{mg}$ of each extract was dissolved in $10 \mathrm{~mL}$ of $1 \mathrm{M} \mathrm{KOH}$ in $10 \%$ aqueous methanol. The mixtures were heated at $100{ }^{\circ} \mathrm{C}$, under nitrogen, for $1 \mathrm{~h}$. The reaction mixtures were cooled, acidified with $1 \mathrm{M} \mathrm{HCl}$ to $\mathrm{pH}$ 2, and then extracted three times with dichloromethane. The solvent was evaporated to dryness.

GC-MS Analysis. Before GC-MS analysis, approximately $20 \mathrm{mg}$ of each dried sample, with a measured amount $(2 \mathrm{mg})$ of internal standard (tetracosane), was dissolved in $250 \mu \mathrm{L}$ of pyridine, and the compounds containing hydroxyl and carboxyl groups were converted into trimethylsilyl (TMS) ethers and esters, respectively, by adding $250 \mu \mathrm{L}$ of bis(trimethylsilyl)trifluoroacetamide and $50 \mu \mathrm{L}$ of trimethylchlorosilane. After the mixture had stood at $70{ }^{\circ} \mathrm{C}$ for $30 \mathrm{~min}$, the derivatized extracts were analyzed by GC-MS $(9,10)$. To check the presence of esterified structures in the extracts, the GC-MS analysis was performed using a trace gas chromatograph 2000 series equipped with a Finnigan Trace MS mass spectrometer, equipped with a DB-1 J\&W capillary column $(15 \mathrm{~m} \times 0.32$ $\mathrm{mm}$ i.d., $0.25 \mu \mathrm{m}$ film thickness) according to the method described by Oliveira et al. $(9,10)$. The extracts were also analyzed by GC-MS, before and after alkaline hydrolysis, using a DB-1 J\&W capillary column $(30 \mathrm{~m}$ $\times 0.32 \mathrm{~mm}$ i.d., $0.25 \mu \mathrm{m}$ film thickness) (10).

Components were identified based on the comparison of their mass spectra with the equipment mass spectral library (Wiley-NIST Mass Spectral Library 1999), on characteristic retention times obtained under the described experimental conditions $(9,10)$ and by comparing their fragmentation profiles with published data (refs 9, 10, 26 and references therein).
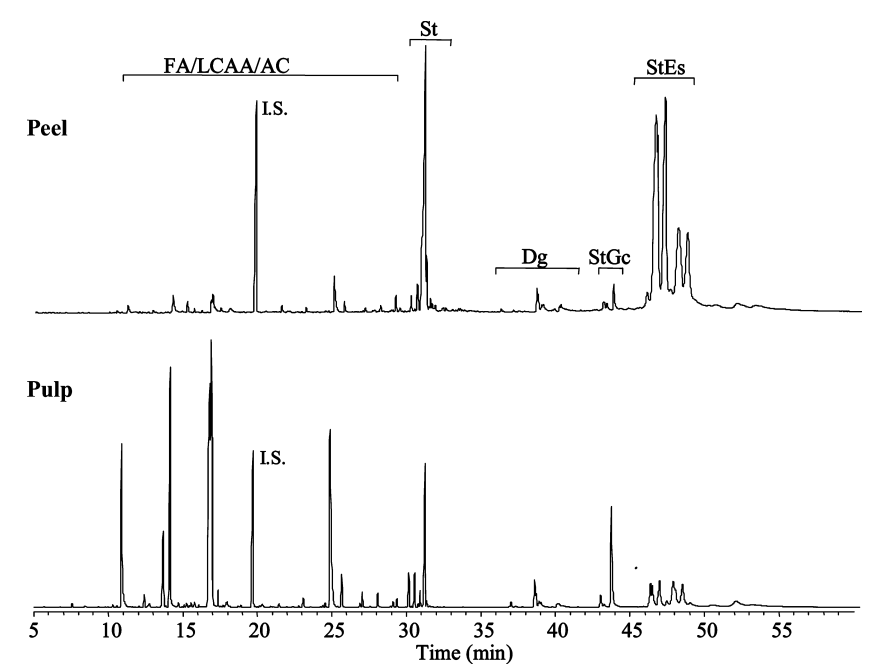

Figure 1. GC-MS chromatogram obtained by a DB-1 $15 \mathrm{~m}$ column of the dichloromethane extract of unripe banana pulp and peel before alkaline hydrolysis. FA, fatty acids; LCAA, long chain aliphatic alcohols; St, sterols; $\mathrm{Dg}$, diacylglycerols; StGc, steryl glucosides; and StEs, steryl esters.

For quantitative analysis, GC-MS was calibrated with pure reference compounds, representative of the major lipophilic extractives components (namely palmitic acid, icosan-1-ol, stigmasterol, and ferulic acid), relative to tetracosane. The respective response factors were calculated as an average of six GC-MS runs.

Two aliquots of each extract were analyzed before alkaline hydrolysis and another two after alkaline hydrolysis. Each aliquot was injected in triplicate. The presented results are the average of the concordant values obtained for each part (less than 5\% variation between injections of the same aliquot and between aliquots of the same sample).

\section{RESULTS AND DISCUSSION}

The yields of the dichloromethane extractives from unripe banana pulp and peel were markedly different, with values of $0.72 \pm 0.007$ and $7.3 \% \pm 0.09 \%$ of dry material weight, respectively. The higher lipidic content of banana peel when compared with that of pulp is in agreement with the results obtained for other Musa varieties (19).

Figure 1 shows typical GC-MS chromatograms of unripe banana pulp and peel extracts, before alkaline hydrolysis, with a $15 \mathrm{~m}$ column. The qualitative composition of the dichloromethane extracts of banana pulp and peel from 'Dwarf Cavendish' is quite similar; however, the abundance of the identified families of lipophilic components differs considerably (Tables 1 and 2). Steryl esters and free sterols are the major lipophilic components found in unripe 'Dwarf Cavendish' banana peel extract, while free fatty acids and sterols dominate in banana pulp extract. Minor amounts of long chain fatty alcohols, diacylglycerols, steryl glucosides, and aromatic compounds, among others, were also identified (Figure $\mathbf{1}$ and Tables $\mathbf{1}$ and 2 ).

Considering that these substrates presented a high content of esterified structures (Figure 1), they were also analyzed by GCMS using a $30 \mathrm{~m}$ capillary column, before and after alkaline hydrolysis, aiming to analyze and quantify the free and esterified lipophilic components, namely, fatty acids, sterols, long chain aliphatic alcohols, and aromatic compounds (Figure 2). Table 1 summarizes the identification of the main lipophilic extractives and the corresponding quantification after alkaline hydrolysis.

Fatty acids represent about 66 and $90 \%$ of the lipophilic components of banana pulp, before and after alkaline hydrolysis, respectively (Figure 2). The banana peel extract, in contrast, presents only 11 and $42 \%$ of fatty acids before and after alkaline hydrolysis, respectively. This considerable increase after hy- 
Table 1. Compounds Identified in the Dichloromethane Extracts of Unripe 'Dwarf Cavendish' Banana Pulp and Peel, after Alkaline Hydrolysis Expressed in $\mathrm{mg}$ of Compound $/ \mathrm{kg}$ of Dry Material ${ }^{a}$

\begin{tabular}{|c|c|c|c|}
\hline $\operatorname{tr}(\min )$ & compound & pulp & peel \\
\hline & fatty acids & 4348 & 7234 \\
\hline & saturated & 1569 & 3376 \\
\hline 23.3 & lauric acid & 5 & 29 \\
\hline 27.1 & azelaic acid & $<5$ & 94 \\
\hline 28.4 & myristic acid & 15 & 51 \\
\hline 30.9 & pentadecanoic acid & 59 & 59 \\
\hline 33.2 & palmitic acid & 1305 & 1990 \\
\hline 35.4 & heptadecanoic acid & 26 & 57 \\
\hline 37.5 & octadecanoic acid & 124 & 312 \\
\hline 39.5 & nonadecanoic acid & 5 & 14 \\
\hline 41.4 & icosanoic acid & 7 & 36 \\
\hline 43.3 & henicosanoic acid & $<5$ & 11 \\
\hline 45.1 & docosanoic acid & 5 & 124 \\
\hline 46.9 & tricosanoic acid & $<5$ & 31 \\
\hline 48.6 & tetracosanoic acid & 12 & 201 \\
\hline 50.2 & pentacosanoic acid & 6 & 53 \\
\hline 51.8 & hexacosanoic acid & $<5$ & 64 \\
\hline 53.3 & heptacosanoic acid & ND & 20 \\
\hline \multirow[t]{2}{*}{57.8} & triacontanoic acid & ND & 230 \\
\hline & unsaturated & 2779 & 3858 \\
\hline 32.5 & palmitelaidic acid & 316 & 78 \\
\hline 36.7 & linoleic acid & 1303 & 1720 \\
\hline 36.8 & $\alpha$-linolenic acid & 553 & 1697 \\
\hline \multirow[t]{2}{*}{36.8} & oleic acid & 607 & 363 \\
\hline & sterols & 530 & 10918 \\
\hline 54.8 & campesterol & 76 & 308 \\
\hline 55.3 & stigmasterol & 65 & 633 \\
\hline 55.6 & 24-methylenepollinastanol & $<5$ & ND \\
\hline 55.8 & 31-norcyclolaudenone & 9 & 2112 \\
\hline 55.9 & cycloeucalenone & 35 & 6517 \\
\hline 56.2 & $\beta$-sitosterol & 325 & 650 \\
\hline 56.3 & n.i. triterpene ketone & ND & 367 \\
\hline 56.3 & isofucosterol & 20 & ND \\
\hline 56.8 & cycloaeucalenol & ND & 100 \\
\hline 56.9 & cycloartenol & $<5$ & 231 \\
\hline \multirow[t]{2}{*}{57.7} & 24-methylenecycloartanol & ND & 103 \\
\hline & aromatic compounds & ND & $<5$ \\
\hline 29.9 & cis-ferulic acid & ND & $<5$ \\
\hline 30.3 & p-coumaric acid & ND & $<5$ \\
\hline \multirow[t]{2}{*}{33.9} & trans-ferulic acid & ND & $<5$ \\
\hline & long chain fatty alcohols & 32 & 503 \\
\hline 31.4 & hexadecan-1-ol & 8 & 33 \\
\hline 35.1 & Z-octadec-9-en-1-ol & 18 & 44 \\
\hline 35.8 & octadecan-1-ol & 6 & 29 \\
\hline 41.1 & henicosan-1-ol & $<5$ & 33 \\
\hline 43.6 & docosan-1-ol & $<5$ & 14 \\
\hline 47.2 & tetracosan-1-ol & $<5$ & 16 \\
\hline 50.5 & hexacosan-1-ol & $<5$ & 58 \\
\hline 53.6 & octacosan-1-ol & $<5$ & 84 \\
\hline 55.0 & nonacosan-1-ol & ND & 36 \\
\hline \multirow[t]{2}{*}{56.5} & triacontan-1-ol & $<5$ & 156 \\
\hline & tocopherols & 10 & 106 \\
\hline 49.5 & $\delta$-tocopherol & ND & ND \\
\hline 51.0 & $\gamma$-tocopherol & $<5$ & 34 \\
\hline \multirow[t]{2}{*}{53.2} & $\alpha$-tocopherol & 10 & 72 \\
\hline & other compounds/nonidentified compounds & 46 & 420 \\
\hline
\end{tabular}

${ }^{a}$ The presented results are the average of the concordant values obtained (less than $5 \%$ variation between injections) for the two aliquots of each sample injected in triplicate. ND, not detected.

drolysis corroborates the presence of significant amounts of steryl esters and diacylglycerols in the original extracts (Table 2). Unsaturated fatty acids, such as linolenic, linoleic, and oleic acids, are the most abundant components of this family in both banana pulp and peel, ranging from 51 to $69 \%$ of the total fatty
Table 2. Compounds Identified in the Dichloromethane Extracts of Unripe 'Dwarf Cavendish' Banana Pulp and Peel before Alkaline Hydrolysis Expressed in $\mathrm{mg}$ of Compound $/ \mathrm{kg}$ of Dry Material ${ }^{a}$

\begin{tabular}{|c|c|c|c|}
\hline $\operatorname{tr}(\min )$ & compound & pulp & peel \\
\hline & diacylglycerols & 119 & 878 \\
\hline 36.8 & 1,2-dipalmitoylglycerol & 13 & 39 \\
\hline 37.1 & 1,3-dipalmitoylglycerol & $<5$ & 46 \\
\hline 38.3 & 1,2-(palmitoyl,linoleoyl)glycerol & 51 & 325 \\
\hline 38.4 & 1,2-(palmitoyl,linolenoyl)glycerol & 30 & 250 \\
\hline 38.6 & 1,3-(palmitoyl,linoleoyl)glycerol & 13 & 91 \\
\hline \multirow[t]{2}{*}{38.8} & 1,3-(palmitoyl,linolenoyl)glycerol & 12 & 127 \\
\hline & steryl glucosides & 292 & 878 \\
\hline 42.8 & campesteryl $3 \beta$-D-glucopyranoside & 30 & 218 \\
\hline 43.0 & stigmasteryl $3 \beta$-D-glucopyranoside & 9 & 137 \\
\hline \multirow[t]{2}{*}{43.5} & sitosteryl $3 \beta$-D-glucopyranoside & 253 & 523 \\
\hline & steryl esters & 469 & 24405 \\
\hline 45.6 & stigmasteryl palmitate & ND & 327 \\
\hline 46.1 & cycloeucalenyl palmitate & 66 & 7441 \\
\hline 46.2 & cycloartenyl palmitate & 67 & 2727 \\
\hline 46.7 & 24-methylenecycloartanyl palmitate & 94 & 7293 \\
\hline $47.6-47.7$ & cycloeucalenyl and cycloartenyl linoleates & 149 & 3790 \\
\hline \multirow[t]{2}{*}{48.2} & 24-methylenecycloartanyl linoleate & 93 & 2827 \\
\hline & nonidentified & 39 & 172 \\
\hline
\end{tabular}

\footnotetext{
${ }^{a}$ The presented results are the average of the concordant values obtained (less than $5 \%$ variation between injections) for the two aliquots of each sample injected in triplicate. ND, not detected.
}

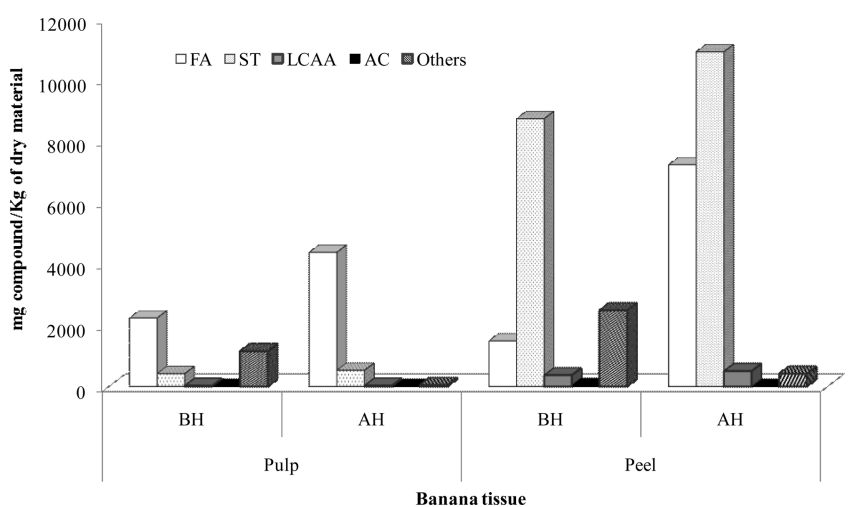

Figure 2. Major families of lipophilic components identified in the dichloromethane extracts of unripe 'Dwarf Cavendish' banana pulp and peel before $(\mathrm{BH})$ and after $(\mathrm{AH})$ alkaline hydrolysis. FA, fatty acids; LCAA, long-chain aliphatic alcohols; ST, sterols; and AC, aromatic compounds.

acids amount (Table 1). Saturated fatty acids are also present, with palmitic, octadecanoic, and triacontanoic acids as the most abundant compounds of this group (Table 1). These results are in agreement with data previously reported for other banana varieties $(19,23)$, where the major fatty acids identified included the lauric, myristic, pentadecanoic, palmitic, linoleic, linolenic, oleic, and octadecanoic acids.

As expected, the major fatty acids identified, before and after alkaline hydrolysis, reflect the composition of diacylglycerols and steryl esters present in these extracts. 1,2-(Palmitoyl,linoleoyl)glycerol, 1,2-(palmitoyl,linolenoyl)glycerol, and 1,3(palmitoyl,linolenoyl)glycerol and steryl palmitates and linoleates are the most abundant diacylglycerols and steryl esters identified, respectively (Table 2).

The amount of sterols in each banana tissue differs significantly, representing $8-13 \%$ of banana pulp and $53-71 \%$ of banana peel lipophilic components. $\beta$-Sitosterol followed by campesterol and stigmasterol are the major sterols found in banana pulp, whereas cycloeucalenone and 31-norcyclolaude- 

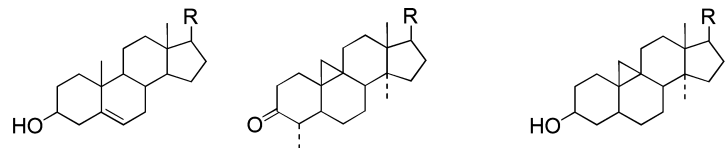

$\mathrm{R}=\mathrm{a}$ Campesterol $\mathrm{R}=\mathrm{b}$ Stigmasterol $\mathrm{R}=\mathrm{c} \beta$-Sitosterol $\mathrm{R}=\mathrm{d}$ Isofucosterol
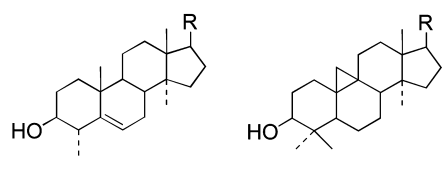

$R=f$ Cycloeucalenol

\section{$R=g$ Cycloartenol}

$\mathrm{R}=\mathrm{f}$ 24-Methylenecycloartanol

SIDE CHAINS (R)
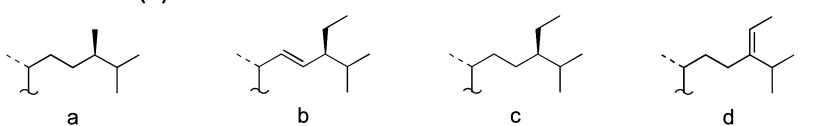

a

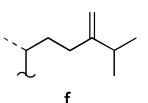

c

d

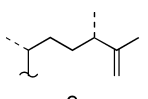

e

$f$

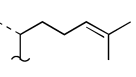

g

Figure 3. Structures of the sterols identified in the unripe banana pulp and peel of 'Dwarf Cavendish'.

none dominate in the banana peel tissue (Table $\mathbf{1}$ and Figure 3); these two triterpenic ketones have been previously identified in the banana peel and flowers of some Musa species $(16,20,24)$ and in smaller amounts in several morphological regions of 'Dwarf Cavendish' (10).

After alkaline hydrolysis, the relative proportion of some sterols, namely, cycloeucalenol, cycloartenol, and 24-methylenecycloartanol, increased slightly, which is in accordance with the steryl esters composition. Indeed, cycloeucalenyl, cycloartenyl, and 24-methylenecycloartanyl palmitates and linoleates were the major steryl esters identified in banana peel and pulp extracts. Minor amounts of stigmasteryl palmitate were also detected in banana peel.

However, considering the extremely high amounts of steryl esters (about $24 \mathrm{~g} / \mathrm{kg}$ ) identified, particularly in the banana peel, the increase in the amounts of sterols (and fatty acids), after alkaline hydrolysis, is lower than expected (Tables 1 and 2). This can be explained based on the resistance to alkaline hydrolysis demonstrated by the steryl esters involving sterols with one and two methyl groups at position C4, like cycloeucalenol, cycloartenol, and 24-methylenecycloartanol, when compared with the 4,4-desmethylsterols such as $\beta$-sitosterol, campesterol, and stigmasterol (27).

Moreover, it is also worth mentioning that the variation in the amounts of sterols with hydrolysis is not related to the presence of steryl glucosides (Figure 1), since these acetal type structures are resistant to alkaline hydrolysis. Campesteryl $3-\beta$ D-glucopyranoside, stigmasteryl 3- $\beta$-D-glucopyranoside, and sitosteryl 3- $\beta$-D-glucopyranoside were detected in banana pulp and peel of 'Dwarf Cavendish' but in slightly smaller amounts than in other banana plant tissues (9). Steryl glucosides account for $270-290 \mathrm{mg} / \mathrm{kg}$ in banana pulp and $870-890 \mathrm{mg} / \mathrm{kg}$ in banana peel, with $\beta$-sitosteryl glucoside as the most abundant component (Table 2). Despite several sterols, steryl esters, and steryl glucosides that had already been identified in other Musa species (15-25), the steryl glucosides identified in this work had never been reported in the banana fruit.

Fatty alcohols represent only a small fraction of the total amount of lipophilic extractives of banana pulp and peel $(0.7-3 \%)$ (Table 1 and Figure 2). The most abundant fatty

alcohols found are those with more than 20 carbon atoms, namely, octacosan-1-ol and triacontan-1-ol (Table 1). The presence of fatty alcohols in the 'Dwarf Cavendish' banana fruit fractions is reported here for the first time.

Finally, some aromatic compounds were also detected, especially in banana peel (Table 1); the slight increase of the hydroxycinnamic acids content after alkaline hydrolysis suggests that these compounds should be esterified in a small extent with other compounds.

Several tocopherols (namely, $\alpha, \delta$, and $\gamma$ ) were also identified, particularly in banana peel, accounting for $22-106 \mathrm{mg} / \mathrm{kg}$ of dry material (Table 1). Studies made in our laboratory showed that during the ripening process, whereas the tocopherol content unchanged considerably in the ripened banana pulp, a significant increase was observed in the ripened banana peel, presenting this tissue with ca. $750 \mathrm{mg}$ of tocopherols per $\mathrm{kg}$ of dry material. This increase in the tocopherol content during the ripening process is in agreement with the results obtained for other fruits (28).

Phytosterols have been recognized for many years by their beneficial effects on human health (35) of which the reduction of blood cholesterol level is the most well-known (14). Steryl glucosides, in particular the sitosteryl glucoside, have deserved particular attention because of their pharmacological activities, such as hepatoprotective (29), anti-inflammatory (30), antimutagenic, and anticancer activities $(31,32)$.

The bibliography covering the biological activity of 4,4-dimethyl sterols and $4 \alpha$-methyl sterols, which are also abundant in the 'Dwarf Cavendish' banana fruit, is quite scarce since these compounds are plant sterol precursors and normally exist at lower levels than the terminal products 4-desmethyl sterols (14). It has been recently reported that the ferulic acid esters of 4,4-dimethyl sterols derived from rice bran oil (under the commercial name of $\gamma$-oryzanol) inhibit tumor promotion, reduce serum cholesterol levels, and can also be used to treat nerve imbalance and menopausal disorders (33). Other studies revealed that cycloartane type and related triterpenoids, including cycloartenyl, 24-methylene cycloartanyl, cycloeucalenyl, cycloeucalenyl palmitate, and cycloeucalenone, can act as chemopreventive agents in chemical carcinogenesis $(34,35)$. Fatty acid steryl esters are also of particular interest in nutraceutical applications such as dermatology, cosmetics, and functional foods. Among the most common sterols and fatty acids used for this purpose are $\beta$-sitosterol, campesterol, stigmasterol, cycloeucalenol and palmitic, linoleic, linolenic, and oleic acids (36). Attending that some of these compounds are present in the banana 'Dwarf Cavendish' already as steryl esters, namely, the stigmasteryl palmitate, cycloeucalenyl palmitate, and cycloeucalenyl linoleate, these fruit residues can be considered as an abundant source of such bioactive compounds.

Together with these phytosterols, the detection of considerable amounts of tocopherols in banana peel, namely, the $\alpha$-tocopherol, that is the most biologically active form of vitamin $\mathrm{E}$ can constitute an important income to banana fruit residues. $\alpha$-Tocopherol is essential for normal growth and development of the human body, and its deficiency often leads to clinical abnormalities. $\alpha-, \delta$-, and $\gamma$-Tocopherols are used as additives in various food products, such as fats and oils, and $\alpha$-tocopherol, in particular, is also used in pharmaceuticals and in cosmetics formulations (37).

In conclusion, lipophilic extracts from banana pulp and peel differ significantly in the content of the major identified families: fatty acids and sterols. The banana pulp lipophilic fraction is composed mainly of fatty acids, especially unsaturated fatty acids, such as linoleic, linolenic, and oleic acids, whereas in banana peel, free sterols and steryl esters are the most abundant 
families with 31-norcyclolaudenone and cycloeucalenone as well as cycloeucalenyl, cycloartenyl, and 24-methylenecycloartanyl palmitates as the major compounds. High amounts of diacylglycerols and steryl glucosides compounds are also present in both tissues, particularly in banana peel.

The present work constitutes, to our knowledge, one of the first detailed studies of the lipophilic fraction composition of banana pulp and peel of 'Dwarf Cavendish'. We believe that the presence of high amounts of fatty acids and, in particularly, of free sterols, steryl esters, and steryl glucosides in this banana fruit species can open new perspectives for the valorization of the fruit residues.

\section{LITERATURE CITED}

(1) FAO. FAO Statistical Databases. Available at http://faostat.fao.org/ site/567/DesktopDefault.aspx?PageID=567 (Accessed May 2008).

(2) Sharrock, S.; Frison, E. Musa production around the world-Trends, varieties and regional importance. In INIBAP Annual Report; INIBAP: Montpellier, France, 1998; pp 42-47.

(3) Emaga, T. H.; Andrianaivo, R. H.; Wathelet, B.; Tchango, J. T.; Paquot, M. Effects of the stage of maturation and varieties on the chemical composition of banana and plantain peels. Food Chem. 2007, 103, 590-600.

(4) Zhang, P.; Whistler, R. L.; BeMiller, J. N.; Hamaker, B. R. Banana starch: Production, physicochemical properties, and digestibility-A review. Carbohydr. Polym. 2005, 59, 443-458.

(5) Hammond, J. B.; Egg, R.; Diggns, D.; Coble, G. C. Alcohol from bananas. Bioresour. Technol. 1996, 56, 125-129.

(6) Tewari, H. K.; Marwaha, S. S.; Rupal, K. Ethanol from banana peels. Agric. Wastes 1986, 16 (2), 135-146.

(7) Bardiya, N.; Somayaji, K. Biomethanation of banana peel and pineapple waste. Bioresour. Technol. 1996, 58, 73-76.

(8) Annadurai, G.; Juang, R. S.; Lee, D. J. Adsorption of heavy metals from water using banana and orange peels. Water Sci. Technol. 2004, 47, 185-190.

(9) Oliveira, L.; Freire, C. S. R.; Silvestre, A. J. D.; Cordeiro, N.; Torres, I. C.; Evtuguin, D. Steryl glucosides from banana plant Musa acuminata Colla var. cavendish. Ind. Crops Prod. 2005, 22, 187-192.

(10) Oliveira, L.; Freire, C. S. R.; Silvestre, A. J. D.; Cordeiro, N.; Torres, I. C.; Evtuguin, D. Lipophilic extractives from different morphological parts of banana plant "Dwarf Cavendish". Ind. Crops Prod. 2006, 23, 201-211.

(11) Oliveira, L.; Evtuguin, D.; Cordeiro, N.; Silvestre, A. J. D.; Silva, A. M. S.; Torres, I. C. Structural characterization of lignin from leaf sheaths of banana plant 'Dwarf Cavendish'. J. Agric. Food Chem. 2006, 54, 2598-2605.

(12) Oliveira, L.; Cordeiro, N.; Evtuguin, D. V.; Torres, I. C.; Silvestre, A. J. D. Chemical composition of different morphological parts from 'Dwarf Cavendish' banana plant and their potential as a nonwood renewable source of natural products. Ind. Crops Prod. 2007, 26, 163-172.

(13) Oliveira, L.; Evtuguin, D.; Cordeiro, N.; Silvestre, A. J. D. Structural characterization of stalk lignin from banana plant, Ind. Crops Prod. 2008, DOI: 10.1016/j.indcrop.2008.04.012.

(14) Moreau, R. A.; Whitaker, B. D.; Hicks, K. B. Phytosterols, phytostanols, and their conjugates in foods: Structural diversity, quantitative analysis, and health-promoting uses. Prog. Lipid Res. 2002, 41, 457-500.

(15) Knapp, F. F.; Nicholas, H. J. The sterols and triterpenes of banana peel. Phytochemistry 1969, 8, 207-214.

(16) Knapp, F. F.; Nicholas, H. J. The distribution of sterols and steryl esters in the banana plant. Phytochemistry 1969, 8, 2091-2093.

(17) Knapp, F. F.; Nicholas, H. J. The sterols and triterpenes of banana pulp. J. Food Sci. 1969, 34, 584-586.

(18) Knapp, F. F.; Phillips, D. O.; Goad, L. J.; Goodwin, T. W. Isolation of 14-methyl-9,19-cyclo-5-ergost-24(28)-en-3-ol from Musa sapentium. Phytochemistry 1972, 11, 3497-3500.
(19) Goldstein, J. L.; Wick, E. L. Lipid in ripening banana fruit. J. Food Sci. 1969, 34, 482-484.

(20) Banerji, N.; Sen, A. K.; Das, A. K. A new 9,19-cyclotriterpene from flowers of Musa paradisiaca (banana). Indian J. Chem. 1982, 21B, 387-388.

(21) Dutta, P. K.; Das, A. K.; Banerji, N. A tetracyclic triterpenoid from Musa paradisiaca. Phytochemistry 1983, 22, 2563-2564.

(22) Ghosal, S.; Saini, K. S. Sitoindosides I and II, two new antiulceragenic sterylacylglucosides from Musa paradisiaca. J. Chem. Res. (S) 1984, 110.

(23) Ghosal, S. Steryl glycosides and acyl steryl glycosides from Musa paradisiaca. Phytochemistry 1985, 24, 1807-1985.

(24) Akihisa, T.; Shimizu, N.; Tamura, T.; Matsumoto, T. (24S)-14,24Dimethyl-9,19-cyclo-5-cholest-25-en-3-ol: A new sterol and other sterols in Musa sapentium. Lipids 1986, 21, 494-497.

(25) Akihisa, T.; Kimura, Y.; Tamura, T. Cycloartane triterpenes from the fruit peel of Musa sapentium. Phytochemistry 1998, 47, 11071110.

(26) Freire, C. S. R.; Silvestre, A. J. D.; Neto, C. P. Identification of new hydroxy fatty acids and ferulic acid esters in the wood of Eucalyptus globulus. Holzforschung 2002, 56, 143-149.

(27) Tenkanen, M.; Kontkanen, H.; Isoniemi, R.; Spetz, P.; Holmbom, B. Hydrolysis of steryl esters by a lipase (Lip 3) from Candida rugosa. Appl. Microbiol. Biotechnol. 2002, 60, 120-127.

(28) Sofia Moco, S.; Capanoglu, E.; Tikunov, Y.; Bino, R. J.; Boyacioglu, D.; Hall, R. D.; Vervoort, J.; De Vos, R. C. H. Tissue specialization at the metabolite level is perceived during the development of tomato fruit. J. Exp. Bot. 2007, 58, 4131-4146.

(29) Banskota, A. H.; Tesuka, Y.; Adnyana, I. K.; Xiong, Q. B.; Hase, K.; Tran, K. Q.; Tanaka, K.; Saiki, I.; Kadota, S. Hepatoprotective effect of Combretum quadrangulare and its constituents. Biol. Pharm. Bull. 2000, 23, 456-460.

(30) Delporte, C.; Backhouse, N.; Negrete, R.; Salinas, P.; Rivas, P.; Cassels, B. K.; San Feliciano, A. Antipyretic, hypothermic and anti-inflammatory activities and metabolites from Solanum ligustrinum Lood. Phytother. Res. 1998, 12, 118-122.

(31) Park, K. Y.; Jung, K. O.; Rhee, S. H.; Choi, Y. H. Antimutagenic effects of doenjang (Korean fermented soypaste) and its active compounds. Mutat. Res. Fundam. Mol. Mech. Mutagen. 2003, $523,43-53$.

(32) Kiriakidis, S.; Stathi, S.; Jha, H. C.; Hartmann, R.; Egge, H. Fatty acid esters of sitosterol 3-beta-glucoside from soybeans and tempe (fermented soybeans) as anti-proliferative substances. J. Clin. Biochem. Nutr. 1997, 22, 139-147.

(33) Luo, H.-F.; Li, Q. L.; Yu, S. G.; Badger, T. M.; Fang, N. B. Cytotoxic hydroxylated triterpene alcohol ferulates from rice bran. J. Nat. Prod. 2005, 68, 94-97.

(34) Akihisa, T.; Yasukawa, K.; Yamaura, M.; Ukiya, M.; Kimura, Y.; Shimizu, N.; Arai, K. Triterpene alcohol and sterol ferulates from rice bran and their anti-inflammatory effects. J. Agric. Food Chem. 2000, 48, 2313-2319.

(35) Kikuchi, T.; Akihisa, T.; Tokuda, H.; Ukiya, M.; Watanabe, K.; Nishino, H. Cancer chemopreventive effects of cycloartane-type and related triterpenoids in vitro and in vivo models. J. Nat. Prod. 2007, 70, 918-922.

(36) Barrault, J.; Boisseau, M.; Pouilloux, Y.; Piccirilli, A. Method for preparing a fatty substance ester and use thereof in pharmaceutics, cosmetics or food industry. U.S. Patent 6,828,451, 2004.

(37) Durant, A. A.; Dumont, M.-J.; Narine, S. S. In situ silylation for the multicomponent analysis of canola oil by-products by gas chromatography-mass spectrometry. Anal. Chim. Acta 2006, 559, $227-233$.

Received for review June 4, 2008. Revised manuscript received August 31, 2008. Accepted September 4, 2008. The Portuguese Foundation for the Science and Technology (FCT) has sponsored this work. L.O. also thanks FCT for the awarding of a postdoctoral grant (SFRH/BPD/38515/2007).

JF801709T 